\title{
RemoDem: delivering support for people with dementia in remote
}

\section{areas}

By Alison Bowes ${ }^{*}$, Alison Dawson*, Louise McCabe*

+Corresponding Author: a.m.bowes@stir.ac.uk (School of Applied Social Science, University of

Stirling, Stirling FK9 4LA, Scotland UK)

*School of Social Sciences, University of Stirling, Scotland

Keywords: dementia; dementia care; remote areas, telecare, care technology

Bowes A, Dawson A \& McCabe L (2018) RemoDem: Delivering support for people with dementia in remote areas, Dementia, 17 (3), pp. 297-314. Copyright (C) The Authors 2016. Reprinted by permission of SAGE Publications. 


\section{RemoDem: delivering support for people with dementia in remote}

areas

\section{Abstract}

RemoDem aimed to develop, test and evaluate services for people with dementia in remote areas of the Faroe Islands, Greenland, Sweden and Scotland. Formative and summative evaluation used a flexible research design including collection of baseline data, interviews and focus groups with key informants and data relating to service users i.e. people with dementia and their carers.

Challenges for service providers included organisational difficulties, lack of clear information about their populations with dementia, lack of knowledge in local communities. Test sites which developed services building on their particular local starting points adopted both specialist and 'off the shelf' technologies, and found these were generally helpful for people with significant support needs.

The flexible research design was found to be essential in the real world conditions of the service development and evaluation. Services were more successful where more mature and less experimental technologies were used. The new services promised to address effectively challenges of remoteness including distance, communication and workforce deployment issues. 


\section{Introduction}

Researchers have argued that the delivery of support for people with dementia in remote areas presents particular challenges internationally. These include issues relating to distance, whereby both staff and people with dementia and their carers may have to travel long distances to deliver support or to consult professionals, such as to obtain a diagnosis (Morgan et al 2011). Specialist care may not be available locally (e.g. Bail et al 2013) and local practitioners may be less well informed (e.g. Greenaway-Crombie et al 2012; Wiese et al 2014). In many remote areas, populations are ageing, with implications for the availability of family support (as families have moved away) as well as for the local workforce, which may be shrinking (e.g. Buckner et al 2013, Buykx et al 2010). In remote areas where new industrial development is providing better paid employment opportunities and in-migration is placing extra demands on services, the workforce pressures can also be significant (Buykx et al 2010). There may also be benefits attached to living in remote areas, in that communities are often close-knit and mutually supportive, making remote areas potentially positive locations in which to age (Keating 2008).

In these circumstances, researchers have identified various measures that may assist in addressing the challenges. Notably, there has been an emphasis on the potential of technological innovation. For example, the use of communications technologies in processes of diagnosing dementia has been found effective in Canada and Shetland (Morgan et al 2009; Innes et al 2012 ). Care technologies which involve the installation of various monitoring devices in people's homes have been found to reduce staff travel time (Lauriks et al 2007) and to support carers (Price 2007). Electronic tracking devices have shown potential to enable people with dementia to get out and about, reducing risks of getting lost (Miskelly 2005, McCabe and Innes 2013). Communications technologies have also been used to promote sociability and social connection for people with dementia (e.g. Meiland et al 2012), sometimes linked with delivery of other specific support such as physical activity sessions (e.g. Askham 2010; Preschl et al 2011). Telemedicine has been widely promoted as supporting people to 
live at home, but there has been a neglect of people with dementia in this research (Ekeland, Bowes and Flottorp 2010).

However, technological innovations have often been considered in isolation as individual measures, and there is only a limited literature which considers them in the context of the 'whole systems' of which they are part (e.g. Steventon et al 2012; Henderson et al 2013). This literature highlights issues relating to local organisations and communities as relevant to the effectiveness of innovation which emerge when a whole systems perspective is adopted.

Previous research also tends to focus on single country cases, and only literature reviews (e.g. Morgan et al 2011) appear to have sought comparative lessons. Whilst cross national comparisons can present difficulties, such as those of ensuring data are both comparable and compared (Hantrais 2009) the apparently shared issues across remote areas in delivering dementia care suggest the utility of considering whether shared lessons can also be identified.

Thus research literature has thus identified several specific challenges for delivery of services for people affected by dementia in remote and rural areas. It has also produced suggested ways of addressing these, notably focused on technology, but also drawing attention to the need to consider innovations in their whole systems contexts and to learn from a comparative approach. It is against this background that the work of the RemoDem evaluation was set.

The RemoDem Project (2012-2014) brought together service provider organisations and academic institutions located in the Northern Periphery of Europe and was funded by the EU Northern Peripheries Programme to address the issues identified above and to test potential solutions, including technological solutions Led by the County Council of Norbotten in Sweden, the project aimed to develop and test integrated service packages for people with dementia living in remote rural communities which allows and supports them to continue living in their current homes and potentially postpones their placement in institutional care. Given this shared aim, there was an 
aspiration to generate cross-national learning across sites, through sharing and comparing experiences. Service delivery partners and test sites were located in the Faroe Islands, Greenland (Semersooq for year 1), Scotland (NHS Western Isles and the Shetland Islands Council) and Sweden (Pajala and Arvidsjaur in Norbotten). Academic partners were Luleå Technological University (Sweden), The Norwegian Centre for Telemedicine and Integrated Care (Norway) and the University of Stirling (Scotland).

This paper describes the RemoDem project and reports the evaluation which was led by the University of Stirling. It will outline the development of a decision support tool to guide service innovation and explore the experiences of the partners and the wider implications and lessons of the work for the delivery of support to people with dementia in remote areas. The involvement of partners from different countries provides a cross-national perspective on these lessons, and permits exploration of how fundamental they are, and the extent to which different contexts affect their salience. The paper will also reflect on some of the challenges of evaluating such projects, highlighting the 'real world' nature of the environments in which service providers must work.

\section{The RemoDem project: overview}

The project developed a decision support too ${ }^{1}$ for service providers to use whilst planning their services. The tool included information about existing research evidence, collated following a structured literature review, and information about potential solutions, including technologies. Each of the test sites worked to review their existing services for people with dementia and identified what they were already doing and what they aspired to do. Thus the starting point for each site was different, according to their existing services and particular local conditions. Once they had decided what they aspired to do, the service providers started to implement their new template of services, rolling them out initially to small numbers of people in their areas, and seeking feedback on their effectiveness. In parallel with the service development, the evaluation progressively established the

\footnotetext{
${ }^{1}$ The decision support tool is available at http://www.remodem.eu/project/products-and-services.aspx
} 
baseline position, documented the new services that were being delivered and examined the characteristics of those in receipt of services. Cross-site learning was facilitated through various events and activities including meetings, focus groups and conferences, as we will detail. The final stage of the project involved identifying wider lessons for future service development and delivery, deriving from the cross-national exploration of experiences.

Throughout, the project adopted a conceptual model of dementia support which placed the self of the person with dementia at the centre of a series of intersecting 'circles of support', bounded by the community in which they live, as represented in Figure 1. The model assumes that peer support, formal and informal sources of support, relevant organisations and local communities as well as the individual themselves all have parts to play in helping a person with dementia to preserve, maintain and nurture their independence and selfhood. The model draws on approaches to dementia care which emphasise personhood and person-centredness, and which take a bio-psycho-social perspective rather than adopting a bio-medical model (Brooker 2003, Kitwood, 1997; Sabat, 2008)).

Figure 1 The RemoDem conceptual model

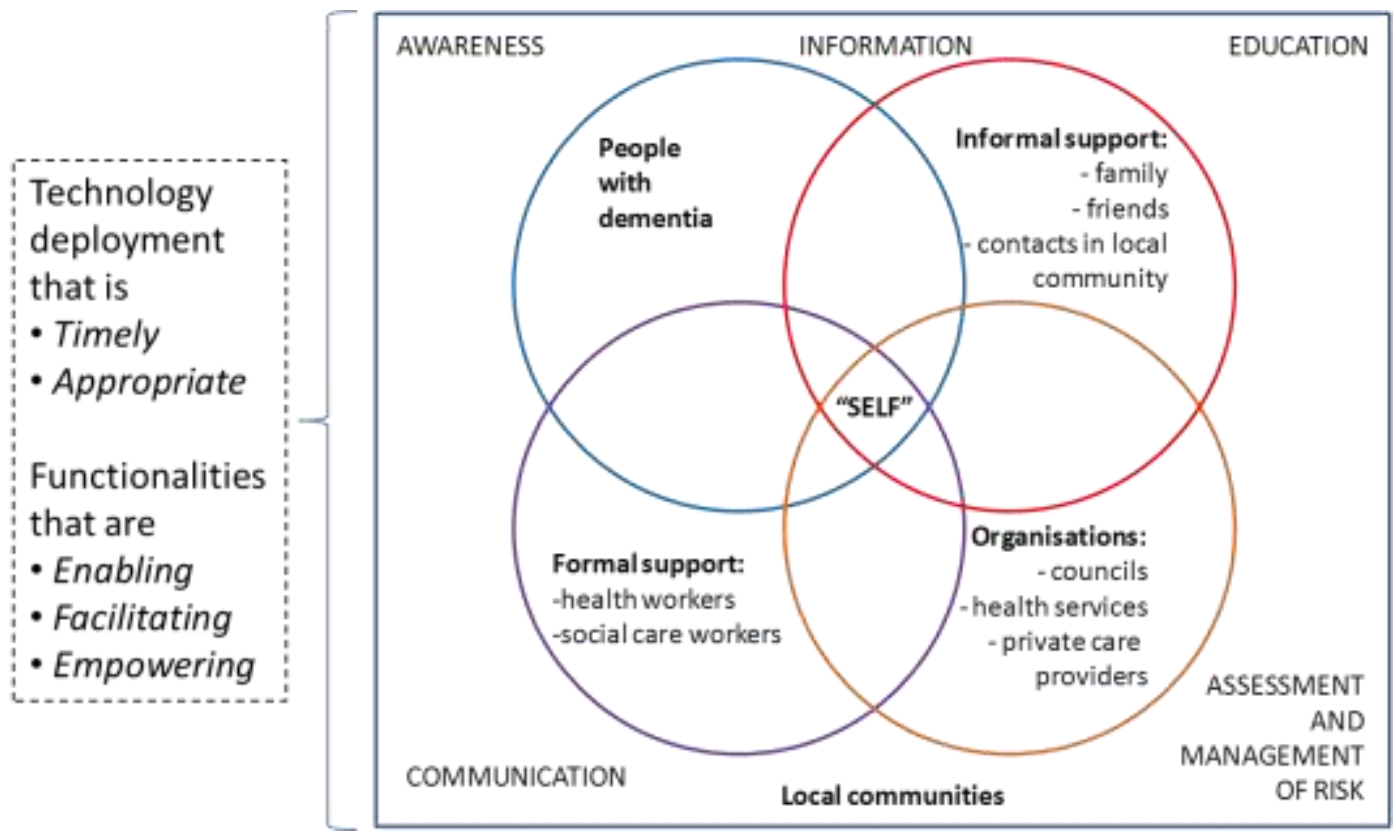


The conceptual model provided the basis for the decision support tool which identified a series of modules of support relating to a range of stakeholder groups. The modules related to direct support of the person with dementia; support for family and other informal carers; support for professionals; support for community members; support for information exchange between organisations; support for community awareness; and support for service integration. Sites were able to browse through the tool and find evidence about 'what works' to support people with dementia, especially evidence about technological solutions.

\section{Methods}

The discussion here focuses on the evaluation of the project. The evaluation was both formative and summative, involving feedback to the partners as the work progressed, as well as providing a final overview of the work. The central aims of the evaluation were to consider how well services were working; what difference they were making for the stakeholders, i.e. people with dementia and their carers, staff and service provider organisations and local communities; and what could be learned from comparing experiences across the sites. Data were collected locally, and then collated and analysed by the University of Stirling team, who reported back to group meetings as well as producing the final evaluation report. The design was a flexible one (Robson 2011), permitting exploratory study, responsive to context, and developing case study material for each site using a combination of qualitative and quantitative methods of data collection and analysis. This approach was selected to permit evaluation in varied, changing and unpredictable contexts.

The first step was to establish a baseline picture of the starting points for each of the sites in terms of the structure of their local older populations and populations with dementia, services currently provided and the policy and practice contexts in which they were working. In addition, sites were asked about their aspirations for the new services. These data were collected from local managers of the social care or health service organisation responsible for delivering care for people with 
dementia through the provision of documents and through interviews conducted by the Stirling team requesting information on the topics listed. Data provided by the sites were incomplete and often patchy, reflecting various local difficulties. As the test site representatives discussed the new service developments, they were requested to provide updates to the evaluation team, who built descriptions of the main service developments in each area.

Once the services were starting to be implemented, the Stirling team leading the evaluation attempted to collect data relating to simple indicators of quality in dementia care, drawing on research literature. We sought information about access to and use of the service; diagnoses of dementia; training taking place; hospital admissions; and admissions to institutional care. These data also proved surprisingly difficult for sites to provide. We also aimed to grasp the possible benefits of the services for people with dementia and their family caregivers, using a questionnaire developed for local administration. This element of the evaluation produced very little data, due to delays in the start of the tests and difficulties for local staff in collecting data when they were prioritising the delivery of long-delayed services. We do not report on these data in the paper. Key informants were used to capture the experiences of developing and delivering the services in each site: the information was collected through a mixture of interviews, discussions at regular on-line team meetings and at annual face to face meetings. Further information came through in-country meetings held between the Faroese, Swedish and the Scottish test sites, at which service providers were able to report and share experiences.

The data collection produced a range of materials - interviews, notes on discussions, documents and statistics provided by the test sites. This range of material exemplifies the flexible approach to data collection that proved necessary: for example, some sites preferred to provide written information, others to take part in interviews or group discussions. The collation of data was done using templates which defined the areas of interest, such as the nature of services already existing and the new ones being developed, and the extent to which the topics in the decision support tool were 
being addressed. The material was then analysed thematically both to identify where key area of interest had been addressed, and to allow themes to emerge. Emerging themes were then discussed with partners to validate and sense check the analysis.

Ethical approval was sought for all the evaluation activity according to local rules. Throughout, principles of informed consent and data confidentiality were upheld, with data on service users being provided to the Stirling team without any identifying material. The identities of individual staff were kept confidential, but the locations have not been concealed, with the agreement of the service provider bodies concerned. The University of Stirling School of Applied Social Science Research Ethics Committee provided ethical approval for the Stirling team to analyse the data provided by the sites. In Scotland, the NHS South East Scotland Research Ethics Service confirmed that NHS ethical review was not required for data to be collected in Shetland and the Western Isles.

\section{Findings}

\subsection{Baseline information: demographics}

All the areas were experiencing population ageing, and had significant populations of older people, particularly in Sweden and Scotland as Table 1 shows. Greenland was an exception, related to markedly lower life expectancy. Age is the most significant risk factor for developing dementia, and each area had therefore identified that the population with dementia would be increasing.

Table 1 Older population in the test sites as a proportion of the total population

\begin{tabular}{|l|l|l|l|l|l|l|}
\hline & $\begin{array}{l}\text { Arvidsjaur } \\
\text { - Sweden }\end{array}$ & Faroes & Greenland & Pajala - & Shetland & Western \\
Population & 2147 & 10338 & 2040 & 2629 & 5447 & 7748 \\
aged 60 and & & & & & & \\
over & & & & & & \\
\hline Total & 5249 & 46469 & 56483 & 6500 & 22210 & 26502 \\
\hline
\end{tabular}




\begin{tabular}{|c|c|c|c|c|c|c|}
\hline population & & & & & & \\
\hline $\begin{array}{l}\% \text { of } \\
\text { population } \\
\text { aged } 60 \text { and } \\
\text { over }\end{array}$ & $41 \%$ & $22 \%$ & $4 \%$ & $40 \%$ & $25 \%$ & $29 \%$ \\
\hline $\begin{array}{l}\text { Life } \\
\text { expectancy }\end{array}$ & 83 & 82 & 71 & 83 & 81 & 81 \\
\hline
\end{tabular}

A difficulty in obtaining figures for dementia prevalence is that rates of diagnosis may be low, and dementia may be a stigmatised and hidden condition. We used Eurocode (http://www.alzheimereurope.org/Research/European-Collaboration-on-Dementia/) data to estimate actual dementia prevalence, and figures provided by the test sites to report diagnoses. As Table 2 shows, in every case except Greenland, these figures suggest under-diagnosis. The figures for Greenland are anomalous, and we are unable to explain them, beyond observing that population structure and environment are so distinct that unexplored factors must be influencing both prevalence and diagnosis rates.

Table 2 Diagnosis and estimated prevalence of dementia in the test sites

\begin{tabular}{|l|l|l|l|l|l|l|}
\hline & Arvidsjaur & Faroes & Greenland & Pajala - & Shetland & Western \\
\hline $\begin{array}{l}\text { Diagnosed } \\
\text { with dementia }\end{array}$ & 72 & 140 & 254 & 47 & 163 & 267 \\
\hline $\begin{array}{l}\text { Estimated } \\
\text { numbers with } \\
\text { dementia }\end{array}$ & 193 & 693 & 61 & 211 & 368 & 538 \\
\hline
\end{tabular}




\begin{tabular}{|l|l|l|l|l|l|l|}
\hline (Eurocode) & & & & & & \\
\hline
\end{tabular}

In every site, support for people with dementia included both informal, often family, care combined with public services. Everywhere except Greenland, individuals contributed financially towards the cost of their care on a means tested basis, with public sources paying the balance.

\subsection{Policies}

Policies varied between countries, though there was everywhere an emphasis on developing improved services and on supporting people to stay longer in their own homes. In Scotland and Sweden, national Dementia Strategies focused on similar issues. In Sweden, these include dementia prevention, early diagnosis, assessment and follow-up for people with dementia, day care, person centred care, multi-professional working and training for staff in supporting people with dementia and in assessing and supporting people with behavioural and psychological symptoms of dementia (BPSD). In Scotland, the National Dementia Strategy and the Dementia Standards together identify key issues for support for people with dementia and stipulate minimum care standards. Identified issues include fear of dementia (seen as an obstacle to seeking diagnosis), poor information for people with dementia and their carers, lack of understanding of dementia among health and care services personnel, widespread failure to treat people with dementia and their carers with dignity and respect and lack of support for informal carers. The Standards then refer to the rights of people with dementia to receive the care and support they need from diagnosis through to end of life care, and set out specific requirements.

The Faroe Islands did not yet have a national strategy, but a recommendation had been made to develop one which would cover service organisation and cooperation, diagnosis, formal social care, legal issues, working with relatives, education and research on dementia. Greenland had a strategy for older people, aimed at supporting them to stay in their own homes as long as possible, and a 
focus on the development of alternative housing as well as residential care for older people no longer able to live at home.

\subsection{Existing services and services aspired to}

Existing services generally emphasised the aspirations for people to remain in their own homes. All the sites had already developed some specialist provision for people with dementia, with some common features including specialist staff (sometimes nurses, sometimes care workers); training for staff working in care settings and in care at home; efforts to raise awareness of dementia; efforts to improve rates and timeliness of diagnoses; and support for family carers, especially through respite and day services.

Use had already been made of various technologies for support at home. In the Faroes, GPS devices, picture phones, reminder calendars and door security systems were already in use. Greenland had used a weekly radio phone-in to discuss issues of dementia and to raise awareness among vastly dispersed communities. In Scotland, community alarms were widely used, and video-links had been employed in Shetland to support processes of diagnosis and reduce the need for people to make three-day long trips to Aberdeen to see specialists (Innes et al 2012). In Sweden, safety alarms had been used in Arvidsjaur, especially to prevent the need for staff to travel widely doing checks on people during the night.

Aspirations rested on what was already being done. The Faroe Islands wanted a national dementia strategy promoting flexible and individual care planning; to extend the use of technologies and train staff better in their use; to improve electronic communication; to instigate preventative home visits, to coordinate day care and respite care; to mobilise multidisciplinary teams and volunteers; and to raise awareness through work in schools and through social media and public events. Greenland wanted to shift from care home provision to more care at home; better conditions and improved skill for care workers. Shetland and the Western Isles highlighted a desire to develop 'dementia friendly communities' and to mobilise local people to support this. The Swedish sites wanted to see 
technology used to support everyday life, including memory support and orientation support, alongside comprehensive developments in services including new support for staff to facilitate working in remote areas, better links across care sectors, improved needs assessment and support for carers.

Overall, every site saw significant need for services to develop, and importantly to be delivered more economically, in the light of the growing client population, constraints on staff availability, and constraints on costs.

\subsection{Services developed}

Each test site developed services according to local conditions and addressing different aspects of the modules identified in the decision support tool. We describe each context in turn, before reviewing some of the stakeholder responses drawn from discussions with key informants.

The Faroe Islands services focused on raising public awareness, trialling technology with people living at home, establishing peer support groups and building a new team of staff specialising in delivering dementia care services. Public awareness events were high profile, with well-known people participating, including a locally popular country singer and a Bishop, as well as people with dementia. The team felt that more people had come forward seeking diagnosis as a result of the events. An end-of-project conference was held in Tórshavn (the capital) and attracted several hundred people, including some who took the opportunity to lobby the politician present and press for continuation of the developing RemoDem services following a forthcoming reorganisation. Various technological devices had been purchased and tried out including specialist items such as orientation boards, memo planners, object finders and telephones with pictures and large buttons, and off-the-shelf items, especially iPads. In reporting on these, the Faroes team noted improvements in communication and in reassurance, and felt this was supporting people with dementia to remain at home. The peer support groups had involved about thirty people, including people with dementia and family members and had provided education, counselling and guidance as well as a forum in 
which people could share experiences and gain mutual support. Around 60 health and social care staff had received training, especially focused on early diagnosis and working with GPs.

In Greenland, awareness raising was also an important focus, and involved public meetings, a radio show, and work with local politicians to improve their knowledge. The team also set out to develop respite care for families, and had made links with GPs to begin looking at whether the awareness raising was leading to more people seeking diagnoses. After the first year however, Greenland was no longer able to participate in RemoDem, because of staffing changes and reorganisation which meant they no longer had capacity.

The Western Isles focused their work on evaluating technologies, staff education and raising awareness. The team purchased several items of technology including the Giraff (a mobile video communication system), pressure mats, memory aids, locator devices, day/night clocks, whiteboards, coloured toilet seats and signs. These were trialled in people's homes and also in local care homes, and the team reported that the lower tech devices seemed to be the most useful. The most high tech device, the Giraff, raised a number of problems, notably negative press coverage ('People with dementia cared for by robots') which was difficult to counter, as well as a practical problem that the local houses were too small and had too much furniture in them for the device to be able to move about successfully. The staff education drew on national programmes of training. The awareness raising work involved media activity, a dementia bus which took information to remote areas, and work with community groups. It later developed into a focus on making Stornoway (the main town) a dementia-friendly community.

The Shetland Islands, whose work was dogged by reorganisations and staff changes, continued to deliver their services including a remote consultation process for dementia diagnosis, care technologies at home including community alarms and GPS tracking devices, movement monitoring in people's homes, and modifying features of people's homes such as floor coverings and lighting to 
make them more dementia friendly. Shetland and the Western Isles frequently shared knowledge and information, and reported that this was particularly useful communication.

In the two Swedish sites, assistive technology was emphasised, and particularly focused on the issues of distance. The communication facilities on the iPad were found to be particularly beneficial for combatting staff isolation. GPS tracking devices were trialled with families who were reported to have found them acceptable and useful. Arvidsjaur had tried out night time cameras for people who had been receiving multiple night time visits, and had seen a reduction of visits in one case. Both the Swedish sites experienced difficulties in getting the services started, mainly due to staffing and organisational issues.

\subsection{Service user characteristics}

Quantitative data on service users was collected for four sites - the Faroes, the two Swedish sites and the Western isles, and provide an overview of the population that received the RemoDem services. Table 3 summarises the characteristics of the people with dementia and their family caregivers.

Table 3 RemoDem participants and their carers at baseline (date of first interview varied)

\begin{tabular}{|l|l|l|l|l|}
\hline & Faroe Islands & Swedish test sites & Western Isles & All test sites \\
\hline pumber of & 15 & 13 & 11 & 39 \\
dementia & & & & \\
\hline $\begin{array}{l}\text { Gender (M=males, } \\
\text { Females) }\end{array}$ & $6 \mathrm{M}, 9 \mathrm{~F}$ & $6 \mathrm{M}, 7 \mathrm{~F}$ & $2 \mathrm{M}, 8 \mathrm{~F}$ & $14 \mathrm{M}, 24 \mathrm{~F}$ \\
\hline $\begin{array}{l}\text { Mean age at } \\
\text { baseline (range of }\end{array}$ & $(45-87)$ & $(\mathrm{n}=10)^{* * * *}$ & \\
ages) & $(\mathrm{n}=15)$ & $(61-99)$ & 78 & 78 \\
$(\mathrm{n}=13)$ & $(64-92)$ & $(42-99)$ \\
\end{tabular}




\begin{tabular}{|c|c|c|c|c|}
\hline $\begin{array}{l}\text { Mean MMSE score } \\
(\text { max score }=30) \\
\text { (range) }\end{array}$ & $\begin{array}{l}22.1 \\
(16-28) \\
\left(n=14^{*}\right)\end{array}$ & $\begin{array}{l}23.4 \\
(17-28) \\
(n=7 * * *)\end{array}$ & $\begin{array}{l}19.9 \\
(15-24) \\
(\mathrm{n}=7)^{* * * * *}\end{array}$ & $\begin{array}{l}21.9 \\
(15-28) \\
(n=28)\end{array}$ \\
\hline $\begin{array}{l}\text { Who participant is } \\
\text { co-resident with }\end{array}$ & $\begin{array}{l}10 \text { with spouse, } 2 \\
\text { with others (son, } \\
\text { daughter and } \\
\text { grand-daughter), } \\
3 \text { living alone }\end{array}$ & $\begin{array}{l}4 \text { with spouse, } 1 \\
\text { with others } \\
\text { (unspecified), } 6 \\
\text { living alone, and } \\
\text { no data for } 2 \\
\text { participants }\end{array}$ & $\begin{array}{l}1 \text { with spouse, } 3 \\
\text { with others (care } \\
\text { home residents), } \\
\text { and } 7 \text { living alone }\end{array}$ & $\begin{array}{l}15 \text { with spouse, } \\
6 \text { with others, } \\
16 \text { living alone, } \\
\text { (no data for 2) }\end{array}$ \\
\hline $\begin{array}{l}\text { Mean age of } \\
\text { spouse or co- } \\
\text { resident other at } \\
\text { baseline in years } \\
\text { (range of ages) }\end{array}$ & $\begin{array}{l}68 \\
(40-86, n=12)\end{array}$ & $\begin{array}{l}72 \\
(64-87, n=4)\end{array}$ & $\begin{array}{l}62 \\
(43-81, n=2)\end{array}$ & $\begin{array}{l}70 \\
(40-87, n=18)\end{array}$ \\
\hline Number of carers & $15^{* *}$ & 13 & 5 & 33 \\
\hline
\end{tabular}

*One Faroese participant had no MMSE score but was described as having 'moderate' dementia severity

**Two carers provided baseline data for one person with dementia, one person with dementia did not have a carer taking part in the evaluation

***Six Swedish participants had no MMSE score, of whom two were described as having 'moderate' and three 'mild' dementia severity, with no data for the remaining participant

$* * * *$ One not recorded

*****Four Western Islanders had no MMSE score, of whom one was described as having 'mild', one 'moderate' and two 'severe' dementia severity respectively

The table indicates that the RemoDem services were being used to support people who were experiencing moderate impairment from dementia, including several who were living alone. As the population figures (table 1) would have predicted, more women than men were receiving services. Whilst these figures are small and preliminary, they do give some reason for optimism that the 
services were reaching those who needed them and meeting the aspirations of the service providers.

Table 4 provides the data on RemoDem service users' capacity to live independently. In this table, the higher the total score, the more areas of difficulty in activities and instrumental activities of daily living the respondent experienced.

Table 4 Summary results from questions on independent functioning at baseline.

\begin{tabular}{|l|l|l|l|l|}
\hline & Faroe Islands & Swedish test & Western Isles & All test sites \\
\hline items, max score 10, (range) & $(0-6)$ & $(0-4)$ & $(0-10)$ & $(0-10)$ \\
\hline Mean ADLs score - 6 items, & 1.5 & 0.8 & 1.3 & 1.2 \\
max score 6, (range) & $(0-5)$ & $(0-3)$ & $(0-5)$ & $(0-5)$ \\
\hline Mean IADLs score 7 items, & 4.5 & 2.8 & 4.1 & 3.8 \\
max score 7, (range) & $(1-7)$ & $(0-6)$ & $(1-7)$ & $(0-7)$ \\
\hline
\end{tabular}

Although the Swedish participants appeared to experience fewer difficulties, these differences are not significant at the $95 \%$ confidence level. Overall, the results suggest that people with considerable difficulties with living independently were still being supported by the services.

\subsection{Reflecting on Developments}

Data on he experiences of each site were thematically analysed to identify what appeared to be emerging issues and challenges, which were then reviewed in focus group discussions, each group involving representatives of each country. The issues related to communities, organisations and people using services.

\section{Communities}


All the communities in the test sites were long established communities, including small towns, villages and large, sparsely populated areas. Three - the Western Isles, Shetland and the Faroes also had remote and inaccessible island communities. All sites except the Swedish ones had experienced de-population, especially out-migration of young people. In Sweden, mining activity had brought new residents with consequent pressure on local services, as well as new employment opportunities.

In every area, there was some stigma attached to the condition of dementia, leading to shame and social isolation to some degree, both for the person with the condition and often for their families. Stigma could result from fear of the condition, making people reluctant to seek diagnosis. It could be less marked where there were local, traditional ways of representing dementia as, for some people, 'normal' ageing: in Shetland, the term 'doitin' was recognised and in the Faroes, the term 'for tidligt alderen' ('too early aged') was a comfortable expression for people to use. All the test sites felt that talking about dementia was becoming more acceptable, and that this was increasing the likelihood of people seeking support from services.

As we described, all the sites had focused on various communication strategies aimed at raising awareness, commonly using media routes including radio, television, print and electronic media. Generally, the media coverage had been positive, disseminating educational messages and providing coverage of the services available through the RemoDem project. However, negative publicity had also resulted, including the coverage of the Giraff and also of the Swedish night-time monitoring services.

\section{Organisations}

Local communities had been engaged in all the sites, through individual communication, through public meetings and through events that involved local people, such as fund-raising and the dementia-friendly community activities. Whilst many of these events had indeed attracted 
audiences and disseminated information as well as encouraging involvement, sites had had mixed success in trying to gain support from local politicians and other decision makers.

Where local champions had supported the RemoDem project, the test sites reported this had helped the organisations to develop services. Champions at senior management and at professional staff levels were both reported to be important. All the sites reported that local voluntary sector organisations could potentially increase the effectiveness of their efforts to communicate with and involve community members, but that they had experienced varying levels of success in engaging the sector.

A challenge that had been faced by all the service provider organisations came from resistance to change, which all had experienced. Staff however were reported to be generally enthusiastic, once they were clear that technology was not going to replace their jobs, but was being tried out to ensure service delivery could continue to a growing population of service users. The RemoDem project tended to blur old boundaries between staff groups, and to stimulate more multiprofessional working, a development that was welcomed by the key informants.

Organisational changes and developments, whilst supporting new service development as teams came together and new teams developed, could also present problems in the development and sustainability of new services. Internal reorganisation meant that the Greenland test site had had to withdraw from the project, Shetland and the Western Isles had experienced changes of personnel, presenting threats to continuity, and the Faroe Islands team were nervous about the possible impacts of an up-coming local government reorganisation which they saw as potentially dissipating the achievement of RemoDem. In Sweden, work to bring together all the teams that needed to be involved in the new service developments significantly delayed the start of the tests.

\section{People using services}


Where technical issues had arisen with devices used, these had created considerable difficulties: notably, the more mainstream technologies had presented fewer problems, and less tried and tested devices which did not work well had delayed the development of the new services. Key informants were very clear that potentially vulnerable service users should not be supplied with technological solutions that did not work well.

Key informants reported that the introduction of technologies was broadly welcomed by people with dementia and their families. Staff support had been important for this, as it could overcome initial reluctance and lack of familiarity. Service users and their families generally found that they could operate the technology as long as it was reliable, sometimes needing help with technical problems. There were few reports of technology being rejected. The most popular kinds of technology used related to time-keeping and orientation, communication over distance, risk reduction and enjoyment. Sometimes, the technology use was not as anticipated; for example an iPad intended for listening to music was used much more for communication and in another case, the iPads were used by staff for mutual support, rather than by the service users as had been originally intended. For people with dementia, the technology was reported as offering increased freedom to go out and increased reassurance, safety and security within the home.

Families were crucial to the success of technology use. They were widely reported as important for initiating the technology request and use; they frequently helped to keep it working; and in many cases they were the 'first responders' if alarms suggested problems. A key outcome for the family caregivers was respite and reduced stress, emphasising the importance for them of knowing what was happening to their relative, without having to make 'just in case' visits. 


\section{Discussion and conclusions}

\subsection{Research design and process}

The adoption of a flexible evaluation design that was adaptable to local circumstances proved most appropriate for the real world situations in which the test sites were operating. Delays were experienced in the time taken to agree and deliver the new services, linked to local reorganisations and changes of personnel, so significant in the case of the Greenlandic site that they withdrew from the project. Using the flexible design, it proved possible to report on developments and to identify issues that have wider resonance for the delivery of services for people with dementia in remote areas. This learning would not have been possible had a controlled design been adopted: such were the environments in which the service providers were operating that the evaluation would most likely have failed.

There are of course implications for the future in terms of developing a better grasp of the impact of new services for communities, organisations, people with dementia and their carers. Firstly, it is clear that the test sites experienced a lack of local data that would give them a clear picture of their populations that would need support and their detailed characteristics. This, they believed, was compounded by issues of under-diagnosis. There is continuing debate about the benefits of early diagnosis of dementia (see, e.g. Le Coteur et al 2013; Fox et al 2013) for individuals: for service providers, it may provide indications of future service need, but relationships between dementia diagnosis and support needs are complex and require deeper qualitative understanding. Second, the collection of evaluation data presents challenges: amongst those encountered in the RemoDem project were issues relating to responsibility for collecting the data and understanding of why it was important. Where the staff collecting the data were directly linked with the RemoDem team, data collection was more successful, whereas in case where front line staff were charged with doing this, their immediate duties tended, probably unsurprisingly, to take precedence. Thirdly, at the start of the project, it was clear that services were somewhat patchy, especially in terms of technology use, 
in which pockets of innovation had occurred, but not in a clearly planned manner. There was pressure on service providers in every area, as the rapid population changes were occurring and the numbers of people with dementia growing. This variation in contexts would also make a controlled study design difficult.

Ekeland et al's (2012) review of methodologies for assessing telemedicine recommends, on the basis of an extensive review of literature that there is a clear role for more formative, naturalistic and collaborative evaluation approaches, including those that involve close engagement with stakeholders: the RemoDem study is a contribution to this recommendation. The social and political embeddedness of care technologies was particularly apparent in the RemoDem project, driven as it was by social change, and affected by political priorities and organisational changes and adaptations in each of the test sites. The evaluation also uncovered a range of relevant cultural variations that appeared to affect the service development and implementation, including issues of stigma, views about caring roles and professional roles, and differences in appropriate ways of engaging public interest and involvement.

\subsection{Technology use in dementia services}

The approach taken in the RemoDem project supported the test sites to adopt technologies that were appropriate to their local circumstances. Each site had a different starting point, one aspect of the 'real world' nature of the work. However, it was notable that sites shared aspirations relating to communication, public awareness and supporting people to remain at home.

It appeared that the technologies that were most effective were those that could be described as 'mature' in that they had already passed through development and testing and had come to a wide market. They included some devices that were especially designed to support care delivery, such as monitoring devices, GPS systems and devices operating as community alarms. The use of iPads was notable in the Swedish and Faroese sites: these commercially available devices had various functions within the project, especially for communication for people with dementia, and also between staff. 
Previous literature has tended predominantly to focus on more specialist devices (cf Evans et al 2011) and the RemoDem project is one of the first to include study of more generally available and popular products.

There is little research which has explored the commercial aspects of care technologies: since the motives of big business are likely to differ from those of public sector service providers, exploration of the implications of this for providing secure, reliable and adaptable services for potentially vulnerable people merits further research. Kubitschke et al's (2010) 16 country study of technology use for supporting older people also raised this point, arguing that the supply side of care technologies is a key, but under-researched, dimension. They note, as we have, that technologies may be specifically designed to support care, more or less mature, or mainstream, with possibilities for use in supporting care. They highlight that larger electronics companies may be increasingly interested in the use of technology to support care, and that currently across Europe, most organisational provision is public. The potential conflicting interests in this rapidly changing field have rarely been considered.

Much research considering care technologies has tended to exclude people with dementia, as it has focused on single conditions and people deemed to have capacity. For example, the Whole System Demonstrator (WSD) projects implemented in England in 2008-2009 included people with diabetes, COPD or heart failure, and not dementia (Steventon et al 2012, Henderson et al 2013). Given that age is a key risk factor for these conditions, as it is for dementia, it seems unsustainable for researchers to exclude the additional challenges that dementia may present. The RemoDem project, specifically focused on dementia, has illustrated the possibility of including people with dementia, and all the test sites had succeeded in doing this.

\subsection{Addressing remoteness}

The RemoDem test sites were addressing some of the issues identified in the literature as arising from remoteness. Distance was one of these for all the sites, and the sites all found that 
technologies including alarms, monitoring and communication devices could be used to reduce the number of times staff and family carers needed to call in, as well as increasing the social engagement of people with dementia living in remote areas. These effects were complemented by the work to inform and engage local communities, building on the resources of local support that exist in close communities.

The test sites recognised that there were ethical issues involved here: fewer visits from staff could potentially deprive a person with dementia of social contact for example. It is helpful here to note the arguments of Baldwin (2006) who emphasises that technology as a thing in itself may be neutral: the context in which it is used however raises questions of the underlying values in operation and influences the ethical choices that are made. The technology can be seen as 'entangled' (Hodder 2012) in the social relations, values and structures in which it is embedded. In the case of the RemoDem project, the underlying values in each site of person centred care and the focus on the selfhood of the person with dementia as being at the centre, seemed generally to be preserved. On some occasions, the staff and local decision makers were perhaps more nervous about using technologies than they needed to be: examples of these are the monitoring devices that observed night time activity (in Sweden) and the widely used GPS devices. In the case of the former, the Swedish sites identified that people preferred not to be interrupted during the night by staff calling in, appreciating that the night camera could detect if they needed a visit or not, and in the case of the latter, reassuring research evidence had demonstrated that people with dementia and their carers were content to use the GPS devices as they valued so highly being able to get out and about (McCabe and Innes 2013).

Communication of many kinds was central to much of the work of RemoDem, as it could be a challenge in remote areas. Aspects of this included disseminating information about dementia and services available, as well as involving local communities in supporting service delivery through, for example, the dementia friendly community initiative in the Western Isles and also service delivery 
itself in the form, for example, of the Shetland remote diagnosis service. A range of technologies used for these included electronic ICT, as well as older technologies such as print media and radio. The focus of the test site aspirations had tended to be communication for the service users and community members and during the course of the project it became clear that communication could also be particularly beneficial for staff, who could be working in isolation and benefit from peer support. The importance of communication of all these kinds is difficult to over-emphasise, and RemoDem has demonstrated its centrality for services in remote areas.

\section{Conclusion}

RemoDem set out to address a fundamental trend experienced in these remote areas of increasing numbers of people with dementia combined with the issues of distance, workforce limitations and diminishing family support. The data collected about the service users demonstrates both the will and the potential to deliver services in these areas to people not only experiencing significant cognitive impairment, but also experiencing difficulties in activities of daily living due to physical infirmity in addition. All the sites were able to deploy technology to assist in their core aspiration to put the person with dementia at the centre and to provide support and care to the person and their carers.

Key lessons from the RemoDem project include the demonstration of the complexity of local circumstances in remote and rural areas in relation to dementia care. Whilst the sites each exhibited some of the challenges reported in the literature, these differed in their expression between contexts. Furthermore, additional challenges emerged, which are probably not specific to remote and rural locations, relating for example to local organisational issues. Both the contextual differences and the other shared challenges indicate some benefits of taking a cross contextual approach which enabled these to emerge.

Secondly, RemoDem offers lessons regarding research design and data collection. The focus on complexity, which contrasts with previous literature that has focused on one area or one aspect of a 
service, necessitates drawing on a range of data sources, and often working with datasets that are difficult to compare and may not be of good quality. In RemoDem, working closely with the delivery teams in each area went some way towards mitigating these difficulties, in that the evaluation was able to collect rich qualitative material on experiences, and to draw on focus group discussions between the teams. Local variations in gathering and recording routine data made the cross national comparison of these particularly difficult: this is a classic problem of cross national comparative research as Hantrais (2009:71) discusses, and necessitates both a reflexive approach, and tactical decision making about how to proceed.

\section{Declaration of conflicts of interest}

Conflicts of interest: none

\section{References}

Askham, E. (2010). All aboard for adventure. Journal of Dementia Care, 18(5), 8-9.

Bail, K., Hudson, C., Grealish, L., Shannon, K., Ehsen, S., Peut, A., Gibson, D., Draper, B. \& Karmel, R. (2013) Characteristics of rural hospital services for people with dementia: findings from the Hospital Dementia Services Project. Australian Journal of Rural Health 21(4), 208-215.

Baldwin, C. (2006). Reflections on ethics, dementia and technology. in Woolham J (ed) Assistive Technology in Dementia Care. Developing the Role of Technology in the Care and Rehabilitation of People with Dementia - Current Trends and Perspectives London: Hawker Publications pp 54-66. Brooker, D. (2003). What is person-centred care in dementia? Reviews in Clinical Gerontology 13(3), 215-222. 
Buckner, L., Croucher, K., Fry, G. \& Jasinska, M. (2013). The impact of demographic change on the infrastructure for housing, health and social care in the north of England. Applied Spatial Analysis and Policy 6(2), 123-142.

Buykx, P., Humphreys, J., Wakerman, J. \& Pashen, D. (2010) A systematic review of effective retention incentives for health workers in rural and remote areas: towards evidence based policy. Australian Journal of Rural Health 18(3), 102-109

Ekeland, A., Bowes, A. \& Flottorp, S. (2010). Effectiveness of telemedicine: a systematic review of reviews. International Journal of Medical Informatics 79(11), 736-771.

Ekeland, A., Bowes, A. \& Flottorp, S. (2012). Methodologies for assessing telemedicine: a systematic review of reviews. International Journal of Medical Informatics 81(1), 1-11.

Evans, N., Harris, N. \& Kuppuswamy, A. (2011). A smarter future: technology to enhance an independent lifestyle for our future selves. International Journal of Therapy and Rehabilitation 18(12), 495-499.

Fox. C., Lafortune, L., Boustani, M. \& Brayne, C. (2013). The pros and cons of early diagnosis in dementia. British Journal of General Practice, 63, e510-512.

Greenaway-Crombie, A., Snow, P., Disler, P., Davis, S. \& Pond, D. (2012) Influence of rurality on diagnosing dementia in Australian general practice. Australian Journal of Primary Health 18(3), 178184.

Hantrais, L., (2009) International Comparative Research: theory, methods and practice, Basingstoke and New York: Palgrave Macmillan and St Martin's Press.

Henderson, C., Knapp, M., Fernandez, J-L., Beecham, J., Hirani, A.P., Cartwright, M., Rixon, L., Beynon, M., Rogers, A., Bower, P., Doll, H., Fitzpatrick, R., Steventon, A., Bardsley, M., Hendy, J. \& Newman, S.P. (2013). Cost effectiveness of telehealth for patients with long term conditions (Whole 
System Demonstrator telehealth questionnaire study): nested economic evaluation in a pragmatic, cluster randomised controlled trial. British Medical Journal 346:f1035.

Hodder, I. (2012). Entangled: an Archaeology of the Relationships between Humans and Things Chichester: Wiley-Blackwell.

Innes, A., McCabe, L., Murdoch, A. \& Vaitheswaran, S. (2012). Evaluation of tele-psychiatry as part of a memory service for people with dementia living in Grampian and the Shetland Islands, report to NHS Shetland, NHS Grampian and the North of Scotland Planning Group \& Millar McKenzie Trust. Available at: http://www.nospg.nhsscotland.com/wp-content/28 12-Shetland-TelepsychiatryReport.pdf [accessed Feb 2015]

Keating, N. (ed) (2008). Rural Ageing: A good place to grow old?. Bristol: Policy Press.

Kitwood, T. (1997). Dementia Reconsidered: The Person Comes First, Open University Press, Philadelphia.

Kubitschke, L., Cullen, K. \& Müller, S. (2010). ICT and Ageing: European Study on Users, Markets and Technologies, Final Report, Brussels: Commission of the European Communities.

Lauriks, S.S., Reinersmann, A.A., Van der Roest, H.G., Meiland, F.J.M., Davies, R.J., Moelaert, F., Mulvenna, M.D., Nugent, C.D. \& Dröes, R.M. (2007). Review of ICT-based services for identified unmet needs in people with dementia. Ageing Research Reviews, 6(3), 223-246.

Le Couteur, D.G., Doust, J., Creasey, H. \& Brayne, C. (2013). Political drive to screen for predementia: not evidence based and ignores the harms of diagnosis. British Medical Journal;347:f5125. McCabe, L. \& Innes, A. (2013). Supporting safe walking for people with dementia: User participation in the development of new technology. Gerontechnology, 12(1), 4-15.

Meiland, F.J.M., Bouman, A.I., Sävenstedt, S., Bentvelzen, S., Davies, R.J., Mulvenna, M.D., Nugent C.D., Moelaert, F., Hettinga, M.E., Bengtsson, J.E., \& Dröes, R.M. (2012). Usability of a new electronic 
assistive device for community-dwelling persons with mild dementia. Aging and Mental Health, 16(5), 584-591.

Miskelly, F. (2005). Electronic tracking of patients with dementia and wandering using mobile phone technology. Age and Ageing 34(5),:497-499.

Morgan, D., Crossley, M., Kirk, A., D’Arcy, C., Stewart, N., Biem, J., Forbes, D., Harder, S., Basra, J., Dal Bello-Haas, V. \& McBain, L. (2009). Improving access to dementia care: development and evaluation of a rural and remote memory clinic. Aging \& Mental Health 13(1), 17-30.

Morgan, D., Innes, A. \& Kosteniuk, J. (2011). Dementia care in rural and remote settings: a systematic review of formal or paid care. Maturitas 68(1), 17-33

Preschl, B., Wagner, B., Forstmeier, S., \& Maercker, A. (2011). E-health interventions for depression, anxiety disorder, dementia, and other disorders in older adults: A review. Journal of CyberTherapy and Rehabilitation, 4(3), 371-385.

Price, C. (2007). Evaluation of an activity monitoring system for people with dementia. Journal of Assistive Technologies, 1(2), 11-17.

Rastad, C., Sjödén, P.O. \& Ulfberg, J. (2005). High prevalence of self-reported winter depression in a Swedish county. Psychiatry and Clinical Neurosciences, 59(6), 666-75.

Robson, C. (2011). Real World Research. Oxford: Blackwell (3 ${ }^{\text {rd }}$ edition).

Sabat, S.R. (2008). A bio-psycho-social approach to dementia. in Downs, M. \& Bowers, B. (eds) Excellence in Dementia Care: Research into Practice. Maidenhead: Open University Press. pp70-84. Steventon, A., Bardsley, M., Billings, J., Dixon, J., Doll, H., Hirani, S., Cartwright, M., Rixon, L., Knapp M., Henderson, C., Rogers, A., Fitzpatrick, R., Hendy, J. \& Newman, S. (2012). Effect of Telehealth on use of secondary care and mortality: findings from the Whole System Demonstrator cluster randomised trial. British Medical Journal 344:e3874. 
Weise, L.K., Williams, C.L. \& Tappen, R.M. (2014). Analysis of barriers ot cognitive screening in rural populations in the United States. Advances in Nursing Science. 37(4), 327-339. 